\title{
Light-Dependent Properties of Finishing and Leather Defects
}

\author{
Claudia Florio*, Gianluigi Calvanese \\ SSIP—Stazione Sperimentale per l'Industria delle Pelli e delle materie concianti, Italian Leather Research Institute, Pozzuoli, Italy \\ Email: ${ }^{*}$ c.florio@ssip.it
}

How to cite this paper: Florio, C. and Calvanese, G. (2021) Light-Dependent Properties of Finishing and Leather Defects. Advances in Materials Physics and Chemistry, 11, 243-253.

https://doi.org/10.4236/ampc.2021.1112020

Received: October 26, 2021

Accepted: December 26, 2021

Published: December 29, 2021

Copyright $\odot 2021$ by author(s) and Scientific Research Publishing Inc. This work is licensed under the Creative Commons Attribution International License (CC BY 4.0).

http://creativecommons.org/licenses/by/4.0/ (c) (i) Open Access

\begin{abstract}
The uniformity of the colour in leathers for the furnishing and automotive sectors is a particularly important feature, especially for white or light-coloured articles, intended to the high-end market; on these articles any colour alteration can be very visible and unpleasant, with possible technical and economic consequences for the producers. In a previous study, we analysed the possible causes behind the formation of some peculiar pink/salmon stains on different kinds of white/beige/light-coloured leather furnishing items, where we focalized our attention on $\mathrm{TiO}_{2}$ properties and its possible interaction with some organic-based antioxidants. In recent years, due to many other similar cases of defects that occurred to tanners and to upholstery traders, we decided to enhance the investigations concerning this topic. More in detail we analysed, defective leathers, powder pigments and chemicals, in order to identify the possible role of some substances in this issue, with particular reference to some antioxidants and aluminosilicates, where several diagnostic techniques have been utilised, as ATR-IR (Attenuated Total Reflectance IR Spectroscopy), SEM-EDX (Scanning Electron Microscopy-Energy Dispersive X-ray Analysis), XRF (X-ray Fluorescence spectrometry), GC-MS (Gas Chromatography-Mass Spectrometry), and DSC/TGA (Differential scanning calorimetry/Thermogravimetry) equipment.
\end{abstract}

\section{Keywords}

Finishing, Pigments, Powder Pigments, Stains, UV-Visible Light-Assisted Chemical Modifications, Surface Optical Properties, Leather Defects, Leather Functionalization, Antioxidants Modifications

\section{Introduction}

Several Italian and international brands of furnishing items are used to produce 
white/light-coloured items, according to consumers preferences and to furniture fashion market requirements. Some of these items can be affected by unpleasant modifications of the original surface colour, different from the most common yellowing [1], where this critical issue normally occurs after several weeks/months from their commercialization. Consequently, in most cases, the producers have no chance to predict this kind of issue, and it will be observed directly by the final consumer.

In a previous SSIP study [2], dedicated to this topic, eight different samples have been analysed, where all these samples were characterised by an alteration of the original surface colour, from white/beige, to pink/salmon. The investigations, firstly, showed that the critical issue was reversible, and disappeared with the exposition of the samples to the visible light $(72 \mathrm{~h}$ of exposition to Xenon lamp, according to the standard UNI EN ISO 105-B02:2014).

SEM microanalysis showed, in both defective and not defective regions of the surface of the samples, a random distribution of tracks of some metals, potentially able to produce coloured compounds as, iron, manganese, lead, cobalt, copper and so on, suggesting that these elements were not correlated to the critical issue. Furthermore, this technique, together with ATR-IR analysis of the surface, suggested that the white coloration was mainly provided by $\mathrm{TiO}_{2}$ based pigments. These techniques also suggested the presence of silicon/aluminium-based compounds on leather surface.

Then, GC-MS analysis of a hexane extract of finishing showed, in the only defective regions, the presence of some organic substances, potentially involved in the critical issue, with particular reference to some carotenoids, that have been correlated to the possible use of antioxidant.

Finally, the GC-MS analysis of volatile substances, showed the presence of other antioxidant agents, as BHT, indirectly related to the critical issue, due to its ability to migration and carriage of other substances.

Definitely, the previous study suggested some hypotheses; more in detail, we supposed that the defect could be mainly related to the presence of some antioxidant; although these substances are normally added to light coloured items in order to avoid the faulty colour degradation, on the other hand, in some environmental conditions, antioxidant are able to migrate, and then to interact with the surface matrix, producing the colour changing; we also supposed that the disappearance of the unpleasant colouration to visible light, could be related to photosensitivity of the agents responsible for the issue and to the possible self-cleaning properties of $\mathrm{TiO}_{2}$.

In recent years, other cases of similar critical issue occurred, where further in-depth analyses were needed.

\section{Materials and Methods}

The recent investigation has been carried out on four samples of defective upholstery leathers. 
Furthermore, we analysed four samples of finishing pigments, having four different shades, normally used for this kind of productions: white, ochre, yellow and lemon [3], where the tanneries providing the defective leather samples used a mixture of these pigments in order to get a point of white closer to beige effect on the surface of their articles, during the finishing production step.

Finally, natural Kaolinite, by Fulka Analitycal has been analysed too.

Natural Kaolinite was also analysed after treatment with alkaline perspiration (UNI EN ISO 11641) in rates $1: 1 \mathrm{w} / \mathrm{v}$, and after treatment with $1 \% \mathrm{w} / \mathrm{w}$ of sodium sulphide.

The defective leather samples were analysed with the following techniques:

- ATR-IR spectroscopy for leather surface/powders characterization, been carried out with a Spectrum One ATR-IR Spectrometer.

- Electron Microscopy and microanalysis, carried out with a Zeiss EVO MA10 Scanning Electron Microscope equipped with an INCA X-act detector.

- GC-MS Chromatography, carried out with an HP GC System/6890-HP/5973 Mass Selective.

- XRF Fluorescence using a ThermoFischer ARL QUANT'X EDXRF spectrometer.

- Early studies of Thermal analysis were carried out with an STDQ600 TA Instrument equipped with a THERMOSTARTM Mass Spectrometer.

The pigments were analysed by ATR-IR spectroscopy.

\section{Results and Discussion}

All the leather samples resulted affected by a change in colour, in wide regions of the surface, where the original white-beige colour of the items turned to a pink, rose shade. No surface colour modifications have been observed in the regions of the items not exposed to any light (Figure 1, photos A and B, showing the original colour of a leather sample, in the regions beyond the stitching).

SEM morphological analysis of the samples showed the presence of more creeps and surface damages among the most defective areas of the items (Figure 1 , photos $C$ and $D$ ), suggesting a possible exposition of these regions to more ageing factors.

For all the leather samples analysed, as we found in the previous study, 24 hours of exposition to Xenon lamp, resulted sufficient to observe the disappearance of the undesired surface coloration. Furthermore, in all the cases, the defect resulted very hard to reproduce, and we only found an increase of the undesired surface colour, in those regions of the samples slightly affected by the defect, after opportune ageing cycles; particularly, we found noticeable effects after the exposure of the samples to $70^{\circ} \mathrm{C}$ for two weeks, in dark conditions, and then to exposure to a wide-field UV lamp for further two weeks, while more relevant effects have been observed, after the repetition of this ageing cycle.

The results obtained after GC-MS analysis of the hexane extract of finishing from the defective samples (previously removed by acetone), suggested the 
presence of some substances indicative of possible use of antioxidants-based product during the finishing operations (Table 1).

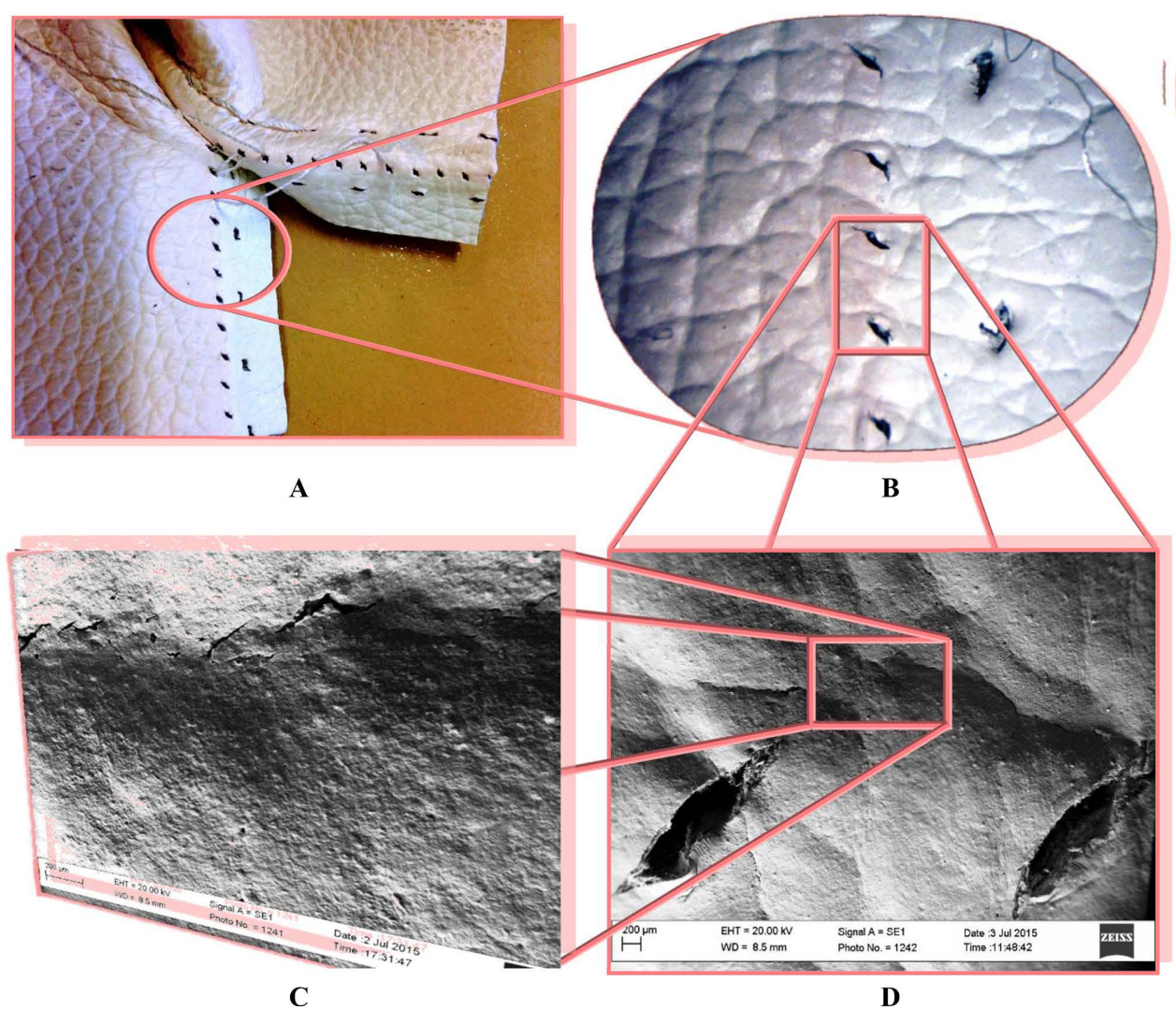

Figure 1. Optical microscope ((A) and (B)) and SEM ((C) and (D)) photos of a defective sample.

Table 1. GC-MS analysis of the hexane extract of finishing of a defective sample.

\begin{tabular}{lccc}
\hline \multicolumn{1}{c}{ Substance } & $\boldsymbol{t}_{\boldsymbol{r}}$ & CAS & Area \% \\
\hline Butyl citrate & 23.8 & $000077-94-1$ & 13.42 \\
1-Docosene & 26.1 & $001599-67-3$ & 1.50 \\
2,2'-Methylen-bis-(4-methyl-6-tert.-butyl-phenol) & 26.6 & $000119-47-1$ & 33.63 \\
11-Tricosene & 27.3 & $052078-56-5$ & 6.65 \\
Pentacosane & 27.7 & $000629-99-2$ & 1.31 \\
1,2-Benzenedicarboxylic acid, mono & 28.6 & $004376-20-9$ & 7.15 \\
Diisooctyl adipate & 31.6 & $001330-86-5$ & 7.17 \\
Squalene & 32.6 & $007683-64-9$ & 1.92 \\
Furo[2,3-H]coumarine, 6-methyl-1-(4-methylphenylamino)- & 40.3 & $298684-60-3$ & 12.73 \\
1-Octadecanethiol & 47.0 & $002885-00-9$ & 6.99 \\
1,2-Bis(trimethylsilyl)benzene & 47.4 & $017151-09-6$ & 2.18 \\
Z-6-Pentadecen-1-ol acetate & 47.5 & $068760-72-5$ & 2.79 \\
Hexadecane, 1-(ethenyloxy)- & 49.5 & $000822-28-6$ & 2.56 \\
\hline
\end{tabular}


Concerning the possible role antioxidant in determining the origin of the critical issue, in the previous work, using the same technique, we found a carotenoid precursor (lycopersene, CAS: $502-62-5$, tr: $39.73 \mathrm{~min}$ ), that we correlated to the issue, and that we didn't found in current analysis (as it is possible to see in Table 1); on the other hand, in the present work we found the presence of 2,2'-Methylen-bis-(4-methyl-6-tert.-butyl-phenol), CAS: 000119-47-1, tr: 26.6 min). This antioxidant can be subject to chromatic alterations due to thermo-climatic aging; although it is more common to observe in this case the yellowing of the product, a further colour change towards pink in over-aging conditions should not be excluded [4] [5] [6].

In addition to the presence of antioxidants, other factors potentially involved in the problem, were observed in the present work.

More in detail, SEM comparative microanalysis of defective and not defective regions of the surface of the samples showed the presence, among the former ones, of a greater amount of aluminium and silicon (Figure 2).

This result has been confirmed by XRF fluorescence surface analysis too (Table 2).

Both results obtained suggested the possible selective migration of aluminium/silicon-based compounds from finishing matrix. This hypothesis seemed to

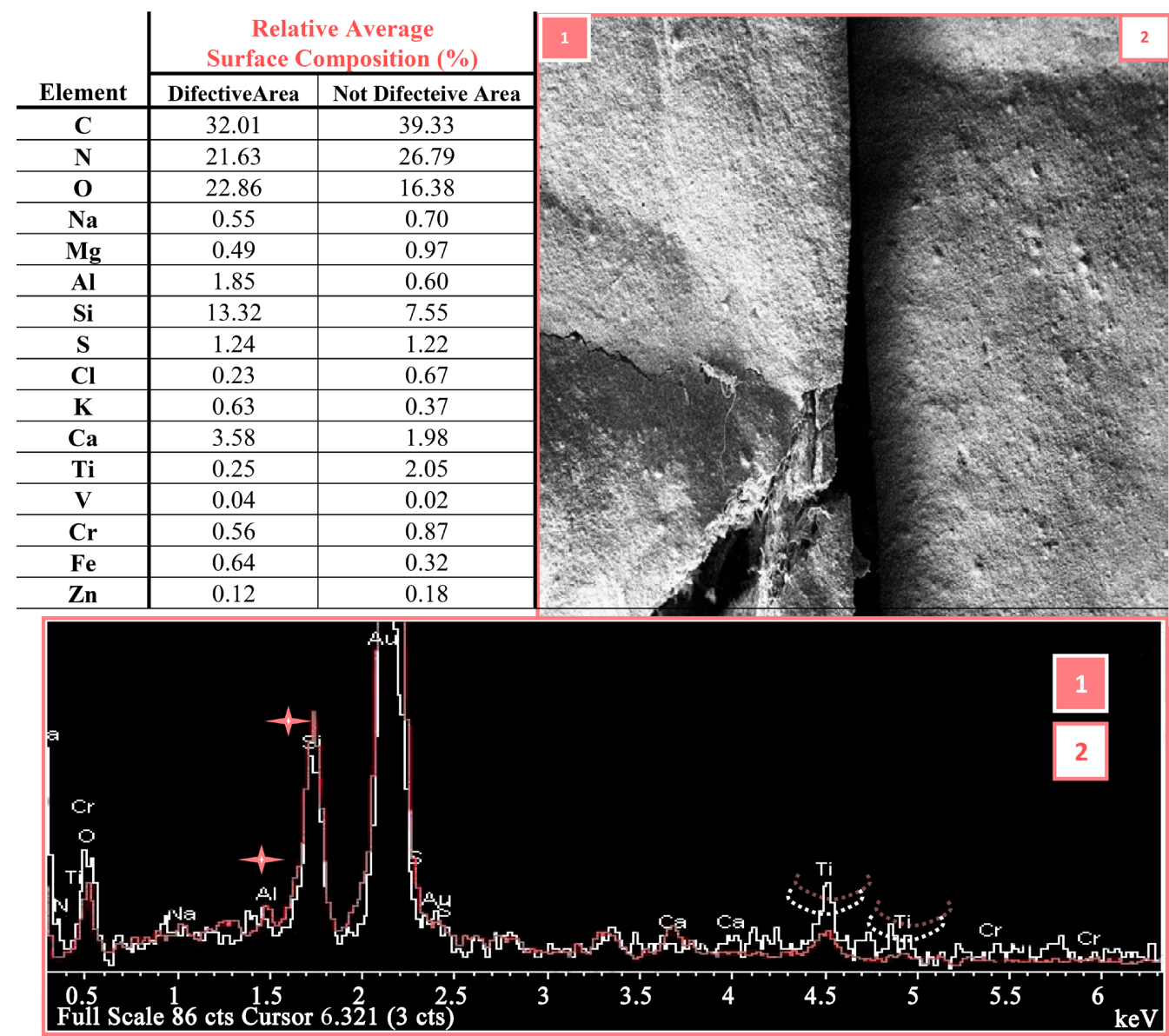

Figure 2. SEM Microanalysis of defective (1) and not defective (2) areas of a defective sample. 
be confirmed by further SEM investigations showing the presence of some pink dot-sized spots on defective areas characterised by a significant amount of aluminium and silicon (Figure 3).

ATR-IR analysis of the powder pigments suggested the presence of kaolinite, $\mathrm{Al}_{2} \mathrm{Si}_{2} \mathrm{O}_{5}(\mathrm{OH})_{4}$, in three out of four of these compounds, even when not expressly

Table 2. XRF fluorescence analysis of defective and not defective areas of a defective sample.

\begin{tabular}{ccccccccc}
\hline & \multicolumn{7}{c}{ Surface Molar Composition (\%) } \\
\cline { 2 - 9 } Points & \multicolumn{7}{c}{ Defective Area } & \multicolumn{3}{c}{ Not Defective Area } \\
\cline { 2 - 9 } & 1 & 2 & 3 & Avarage & 1 & 2 & 3 & Avarage \\
\hline $\mathrm{Zn}$ & 1.6420 & 1.6960 & 1.5770 & 1.6383 & 1.7590 & 1.7460 & 1.7060 & 1.7370 \\
$\mathrm{Al}$ & 0.3070 & 0.3810 & 0.3110 & 0.3330 & 0.0000 & 0.0000 & 0.0000 & 0.0000 \\
$\mathrm{Si}$ & 15.3970 & 15.4590 & 16.1280 & 15.6613 & 15.1750 & 14.9830 & 14.8330 & 14.9970 \\
$\mathrm{~S}$ & 3.7830 & 3.8670 & 3.6300 & 3.7600 & 3.8900 & 3.8850 & 3.8370 & 3.8707 \\
$\mathrm{~K}$ & 1.0190 & 0.8480 & 0.3330 & 0.7333 & 0.2800 & 0.1940 & 0.2950 & 0.2563 \\
$\mathrm{Ca}$ & 4.0860 & 4.0620 & 4.5610 & 4.2363 & 2.7440 & 2.8400 & 2.9400 & 2.8413 \\
$\mathrm{Ti}$ & 60.3700 & 60.9300 & 60.5800 & 60.6267 & 62.2600 & 62.1100 & 62.0100 & 62.1267 \\
$\mathrm{~V}$ & 0.2850 & 0.0850 & 0.3550 & 0.2417 & 0.0980 & 0.2690 & 0.0490 & 0.1387 \\
$\mathrm{Cr}$ & 11.8930 & 11.5280 & 11.4000 & 11.6070 & 12.7010 & 12.8600 & 13.1130 & 12.8913 \\
$\mathrm{Mn}$ & 0.4660 & 0.4840 & 0.4730 & 0.4743 & 0.5240 & 0.5250 & 0.6380 & 0.5623 \\
$\mathrm{Fe}$ & 0.5110 & 0.4960 & 0.4650 & 0.4907 & 0.4650 & 0.4610 & 0.4500 & 0.4587 \\
$\mathrm{Total}$ & 99.7590 & 99.8360 & 99.8130 & 99.8027 & 99.8960 & 99.8730 & 99.8710 & 99.8800 \\
\hline
\end{tabular}

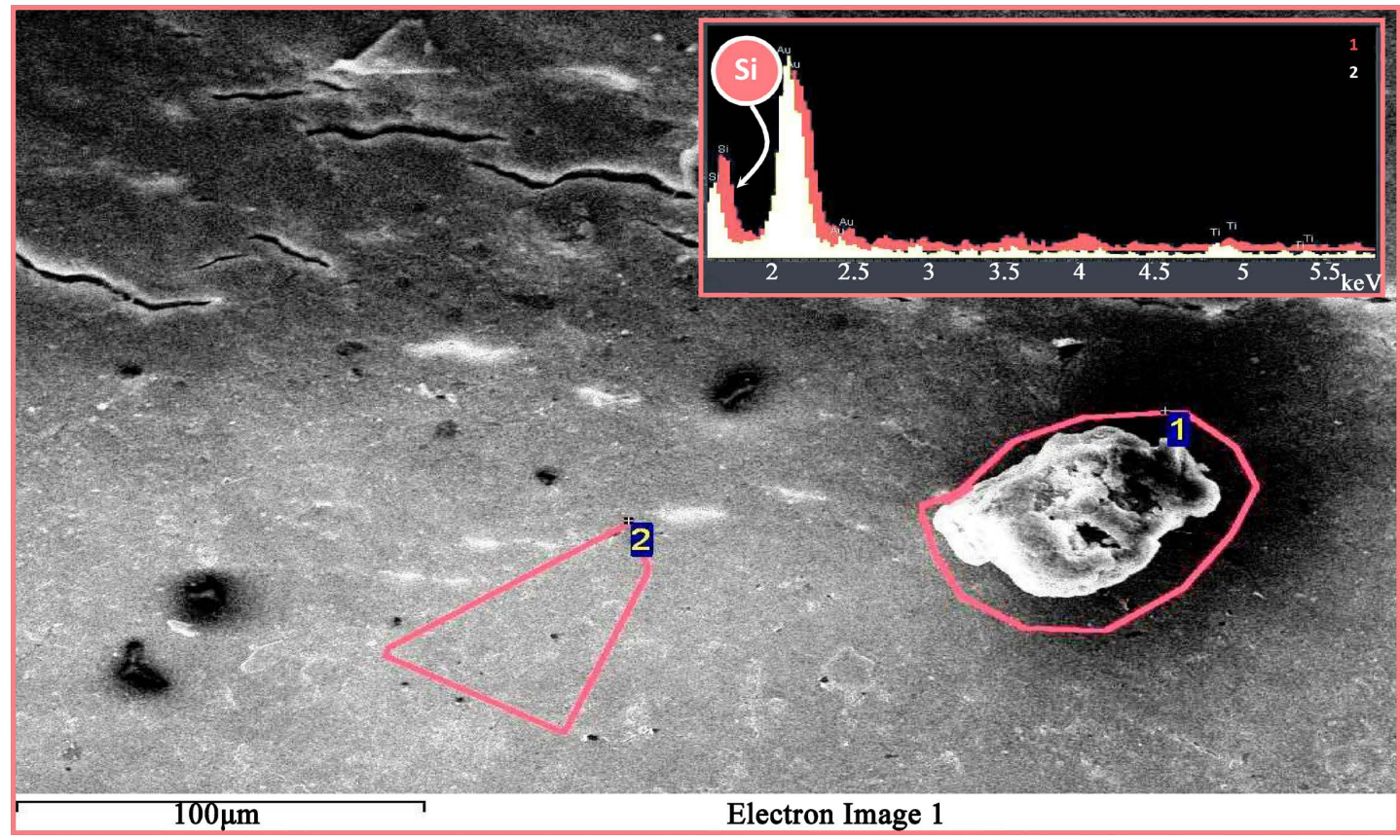

Figure 3. SEM microanalysis of a defective area. 
indicated in the technical and safety data sheets, where the use of similar aluminosilicates as components of commercial pigments is known, as well as the possible tendency to colour modifications exhibited by such substances [7] [8] [9] (Figure 4).

Spectroscopic IR analysis of leather surfaces provided some interesting results; more in detail we noticed that, in most cases, in spite of the greater amount of aluminium and silicon observed in the most defective regions of the samples, by SEM microanalysis, less strong IR signals indicative of $\mathrm{OH}$ stretching of kaolinite, were found among these areas (Figure 5). This outcome suggested the possible

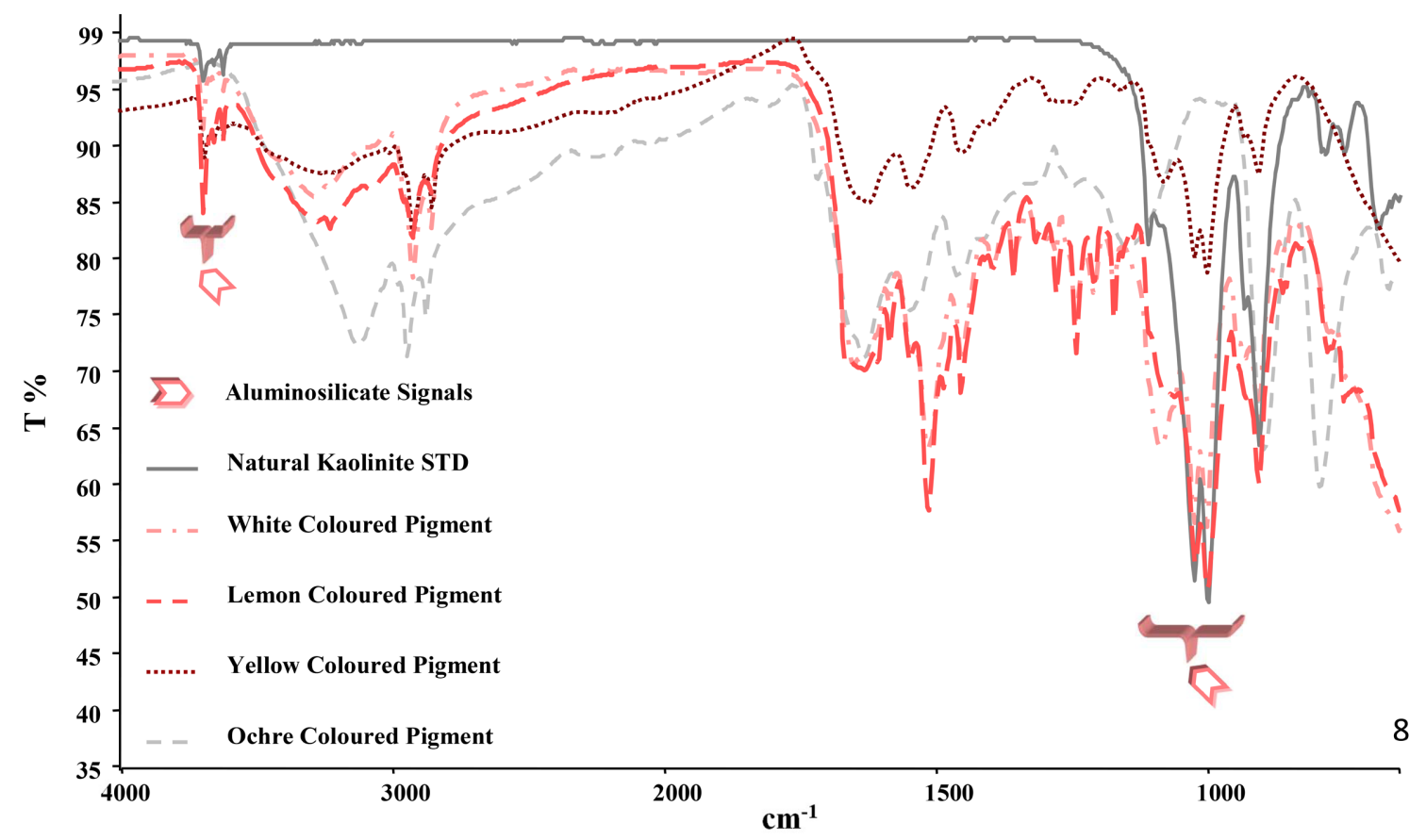

Figure 4. Overlap of the IR spectra of kaolinite and finishing pigments.

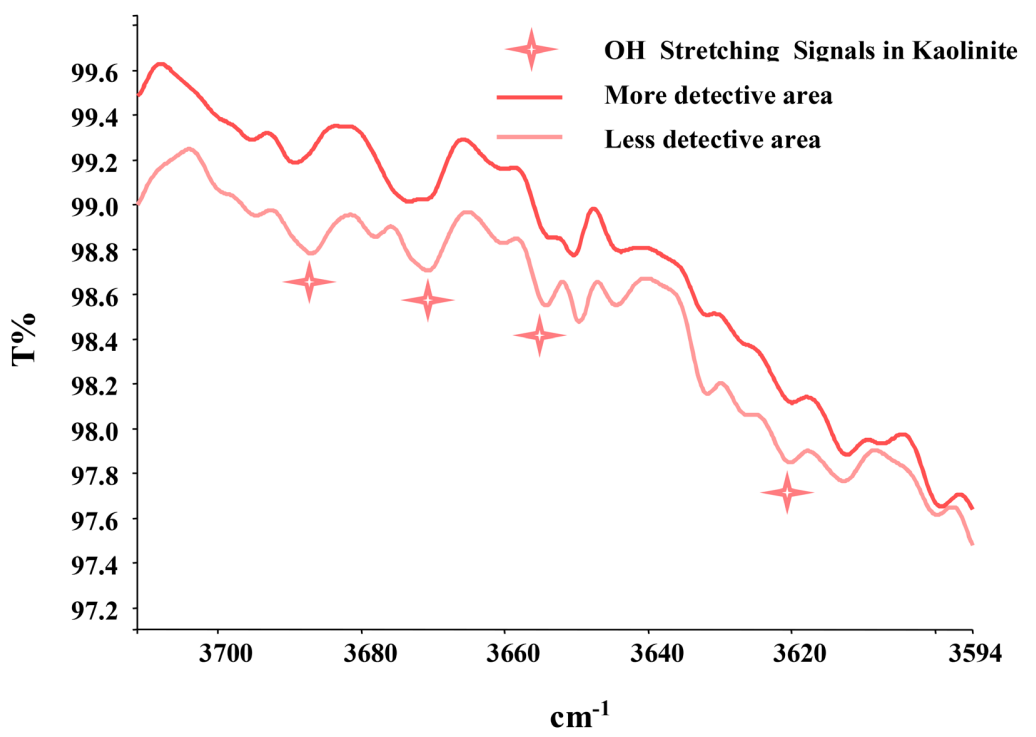

Figure 5. Overlap of the IR spectra of different surface regions of a defective leather sample. 
partial degradation of kaolinite, in more defective areas. Also thermal analysis of the upper layer of finishing of the leather samples (previously removed mechanically from the surface by a little blade) seemed to confirm this hypothesis, due to a lower signal registered, among these areas, between $450^{\circ} \mathrm{C}$ and $600^{\circ} \mathrm{C}$, compatible with the possible dehydroxylation of kaolinite (suggesting that this phenomenon could have already occurred in more defective areas).

Literature reports that, under given chemical-physical conditions (as ageing at high temperatures in alkaline conditions in presence of $\mathrm{NaCl}$ salts), kaolinite could be affected by alteration into sodalite, $\mathrm{Na}_{8} \mathrm{Al}_{6} \mathrm{Si}_{6} \mathrm{O}_{24} \mathrm{Cl}_{2}$ (mineralogically classifiable as feldspathoid) [10] [11], where, some species of this substance (as Hackmanite), especially in presence of dopant elements, as sulphur (as sulphide ion), could exhibit peculiar optical properties [12] [13], with consequent changing in colour, from colourless to pink. In the following the schematic behaviour of some tenebrescent sodalite (Hackmanite) is reported (Figure 6).

We supposed that, since leather is a complex matrix, some components, as the chemicals used during the tanning process, could provide the opportune chemical conditions, able to promote the possible modification of kaolinite; furthermore, eventual contact of the surface with given substances deriving from anthropic contamination (as the ones deriving from human perspiration), besides some possible environmental, ageing conditions, could contribute to determine similar phenomena, with consequent changing of leather surface colour.

In order to evaluate this possibility, some peculiar chemical treatments and ageing tests were carried out, on natural kaolinite; more in detail, kaolinite powder was wetted with alkaline perspiration (UNI EN ISO 11641) in rates 1:1 $\mathrm{w} / \mathrm{v}$, and treated with $1 \% \mathrm{w} / \mathrm{w}$ of sodium sulphide; then it was aged at $70^{\circ} \mathrm{C}$ for four weeks, and finally exposed to a wide-field UV lamp for further four weeks. After both the chemical treatment and the ageing, we noticed a slight change in colour of the powder, from white to light, pale pink, were the only ageing didn't produce any kind of similar effect, while the only chemical treatment produced only a slight yellowing (Figure 7).

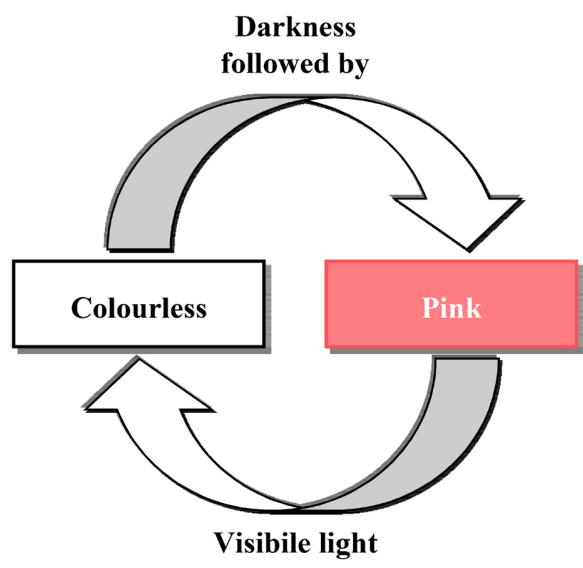

Figure 6. Colour change in sodalite (Hackmanite). 


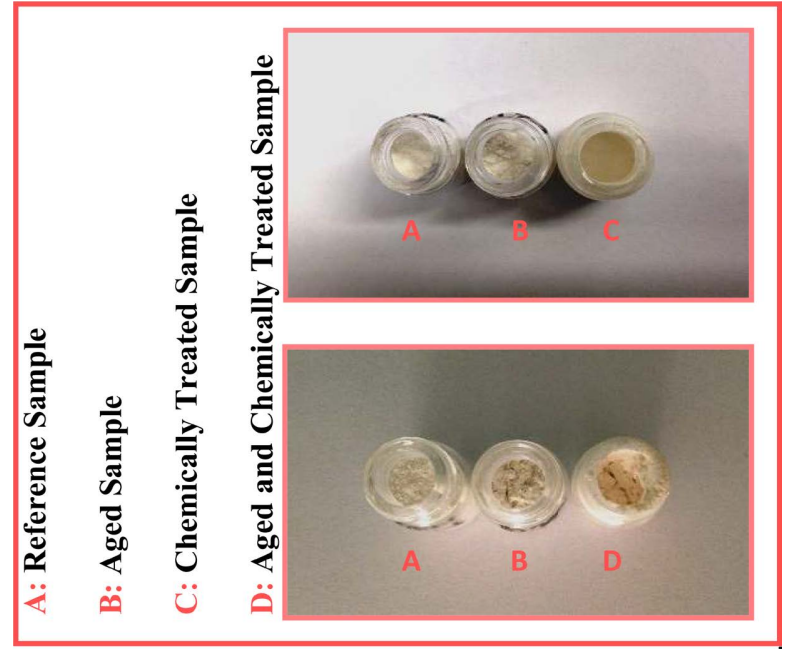

Figure 7. Results of chemical-physical treatments of kaolinite.

These results suggested a possible contribution of aluminosilicates modifications into species characterised by light-dependent properties, in the occurrence of the issue of the analysed samples, where, on the other hand, the whole critical issue seemed to be due, firstly to the instability of finishing compounds, with consequent migration and separation of some pigments, fillers and antioxidant from finishing matrix, potentially produced by ageing factors. Finally we didn't exclude the possible indirect role of specific features of the whole items in the critical issue occurrence; this last evaluation seemed to be confirmed by specific technical claims of some manufacturers about the possible role of raw materials in surface instability, where, more in detail, one of them revealed that the defect occurred mainly when some kinds of crust leathers, with a given territorial origin, were processed, whose finishing being equal to the one of not defected artefacts.

\section{Conclusions}

The results obtained from both previous and present studies, definitely suggested that this peculiar issue, concerning the surface colour change of upholstery items, could be related to a possible two-steps phenomenon: the former step was identified with a possible process of selective migration of pigments, antioxidants and fillers on the leather surface, due to a possible inadequate dosage and consequent instability of the finishing, as well as to a possible aging condition able to foster this migration; the latter step was supposed to be associated to the possible modification of these components, under given chemical-physical conditions, provided by different possible factors (deriving, for example, by the production process, by ageing/environmental conditions, anthropic contamination, etc.) into species exhibiting light-dependent properties; more in detail, the present work suggested the possible contribute of both antioxidant and aluminosilicates modifications into species characterised by light-dependent features, in the occurrence of the critical issue. Finally, the reached outcomes, could im- 
prove the understanding of the mechanisms behind these phenomena, and could allow the planning of possible surface functionalization of leathers by use of nanostructured materials, able to foster the shift of absorption towards the region of visible and improve its self-cleaning functions.

Future developments of the study will include the analysis of a greater number of samples and the diagnostic insights particularly focused on greater use of thermal analysis techniques.

\section{Acknowledgements}

We wish to thank the colleagues from the Department of Industrial Engineering-NANO-MATES Center of the University of Salerno, for their support in XRF Fluorescence analysis of leather samples.

\section{Conflicts of Interest}

The authors declare no conflicts of interest regarding the publication of this paper.

\section{References}

[1] Florio, C., Aveta, R., Calvanese, G. and Naviglio, B. (2019) Advanced Diagnostics and Innovative Solutions for Leather Defects: The Problem of Yellowing. Journal of the Society of Leather Technologists \& Chemists (JSLTC), 103, 296-304.

[2] Florio, C., Calvanese, G., Naviglio, B., Mascolo, R. and Grasso, G. (2009) Difetti di rifinizione: Un caso particolare su pelli con rifinizione pigmentata a base di $\mathrm{TiO}_{2}$. CPMC 85-n.3.

[3] Eastaugh, N. (2005) The Pigment Compendiu: A Dictionary of Historical Pigment. Elsevier, Amsterdam.

[4] Hill, D.M. (2019) Latex Dipping: Science and Technology. De Gruyter. https://doi.org/10.1515/9783110638097

[5] Fleck, J.E. (1997) Oven Aging Antioxidant Study to Alleviate Yellowness upon Warehouse Storage. Internal Technical Report, Ampacet Corp., Terre Haute.

[6] Pospíšil, J. (2008) Transformation of Phenolic Antioxidants and the Role of their Products in the Long-Term Stabilization of Polymers. Properties of Polymers, Advances in Polymer Science-POLYMER, 36, 69-133. https://doi.org/10.1007/3-540-10204-3 3

[7] Kowalak, S. and Jankowska, A. (2003) Application of Zeolites as Matrices for Pigments. Microporous and Mesoporous Materials, 61, 213-222. https://doi.org/10.1016/S1387-1811(03)00370-6

[8] Yan, Q., Lei, Y. and Yuan, J. (2009) Preparation of Titanium Dioxide Compound Pigments Based on Kaolin Substrates. Journal of Coatings Technology and Research, 7, 229-237. https://doi.org/10.1007/s11998-009-9172-6

[9] Sarkodie, B., Asinyo, B.K., Xun, Z. and Tawiah, B. (2019) Characteristics of Pigments, Modification and Their Functionalities. Color Research \& Application, 44, 396-410. https://doi.org/10.1002/col.22359

[10] Novembre, D., Gimeno, D., Pasculli, A. and Di Sabatino, B. (2010) Synthesis and Characterization of Sodalite Using Natural Kaolinite: an Analytical and Mathematical Approach to Simulate the Loss in Weight of Chlorine during the Synthesis 
Process. Fresenius Environmental Bulletin, 19, 1109-1117.

[11] Zhao, H., Deng, Y., Harsh, J.B., Flury, M. and Boyle, J.S. (2004) Alteration of Kaolinite to Cancrinite and Sodalite by Simulated Hanford Tank Waste and Its Impact on Cesium Retention. Clays and Clay Minerals, 52, 1-13. https://doi.org/10.1346/CCMN.2004.0520101

[12] Chan, I.F. and Onton, A. (1973) Optical Properties of Photochromatic Sulfur-Doped Chlorosodalite. Journal of Electronic Materials, 2, 17-46. https://doi.org/10.1007/BF02658102

[13] Kirk, R.D. (1955) The Luminescence and Tenebrescence of Natural and Synthetic Sodalite. American Mineralogist, 40, 22-30. 